\title{
IDEOLOGIAS ORGANIZACIONAIS: UMA CRÍTICA AO DISCURSO EMPREENDEDOR
}

\author{
Alessandra de Sá Mello da Costa ${ }^{1}$ \\ Luiz Alex Silva Saraiva ${ }^{2}$
}

\section{Resumo}

A presente pesquisa teve por objetivo identificar quais discursos hegemônicos emergem acerca do empreendedorismo nos espaços organizacionais das empresas juniores brasileiras e quais seriam seus possíveis desdobramentos. De forma a alcançar este objetivo, conduzimos uma pesquisa qualitativa, orientada epistemologicamente pelo interpretativismo e metodologicamente pela análise crítica do discurso. Foram realizadas 60 entrevistas com estudantes e professores participantes de seis empresas juniores, tanto do âmbito público quanto do âmbito privado. A análise permitiu identificar um conjunto de objetos discursivos associados ao empreendedorismo, quais sejam: (1) o consenso acerca da centralidade da empresa na constituição do pensar e do agir do indivíduo no mundo; (2) a exemplaridade dos modelos empreendedores capitalistas neoliberais; e (3) a ausência de alternativas viáveis ao capitalismo contemporâneo. As três ordens de discursos identificadas nos permitiram argumentar que o discurso empreendedor contribui, de forma ideológica, tanto para que a empresa capitalista contemporânea seja compreendida como único modelo possível de geração de riqueza, de renda e de trabalho na sociedade quanto para que a educação superior seja constituída menos um instrumento de emancipação humana do que um mecanismo de reprodução do capital.

Palavras-chave: Empreendedorismo; Empresa Junio; Ideologia Empreendedora; Discurso; Análise do Discurso

\section{ORGANIZATIONAL IDEOLOGIES: A CRITIQUE OF ENTREPRENEURIAL DISCOURSE}

\begin{abstract}
\footnotetext{
${ }^{1}$ Professora Adjunta do IAG - PUC-Rio. E-mail: alessandra.costa@iag.puc-rio.br.

2 Professor Adjunto do CEPEAD - UFMG. E-mail: saraiva@face.ufmg.br
}

This articles aims to identify the orders of discourse that emerge from existing entrepreneurial discourse within Junior Enterprises in Brazil, assuming that, the interdiscursive relations regarding this subject do ideologically contribute to the construction of the contemporary capitalist 
enterprise as the only possible model for the generation of wealth in society. We carried out a qualitative survey that was epistemologically orientated by interpretivism, and methodologically orientated by critical discourse analysis. In addition, 60 interviews were carried out with students and professors, which allowed the identification of three orders of discourse: (1) a consensus regarding the centrality of companies in terms of thinking and acting of a given individual in the world; (2) the exemplarity of the neoliberal capitalist entrepreneurial model and (3) the absence of feasible alternatives for the contemporary capitalism model. The conclusions allows to think that the hegemonic discourses on entrepreneurship suggesting that high education has been less of a human emancipation tool and more of a capital reproduction mechanism.

Key Words: Entrepreneurship; Junior Enterprise; Entrepreneurial Ideology; Discourse; Discourse Analysis.

\section{IDEOLOGÍAS DE LA ORGANIZACIÓN: UNA CRÍTICA DEL DISCURSO CONTEMPORÁNEO SOBRE EL EMPRENDEDORISMO}

\section{Resumen}

Esta investigación tuvo como objetivo identificar los discursos hegemónicos que emergen sobre el espíritu empresarial (emprendedorismo) en los espacios de organización de junior enterprises brasileños y cuáles son sus posibles resultados. Para lograr esto, se realizó una investigación cualitativa, guiada epistemológica y metodológicamente por interpretativismo e por el análisis crítica del discurso. El análisis (com alumnos y profesores de seis junior enterprises) identificó un conjunto de objetos discursivos asociados a la iniciativa empresarial, a saber: (1) el consenso sobre la importancia de la empresa en la constitución de pensar y de actuar del individuo en el mundo; (2) la ejemplaridad de los modelos neoliberales capitalistas; y (3) la ausencia de alternativas viables al capitalismo contemporáneo. Los tres órdenes de discursos identificados nos permitió argumentar que el discurso empresarial contribuye en forma ideológica, tanto es así que la empresa capitalista contemporánea se entiende como el único modelo posible de creación de riqueza, el ingreso y el trabajo en la sociedad y para la educación superior es constituido menos un instrumento de emancipación humana que un mecanismo de reproducción del capital.

Palabras clave: Emprendedorismo; Junior Enterprises; Organización; Ideologia; Discurso. 


\section{Introdução}

O tema do empreendedorismo vem sendo cada vez mais valorizado como base do crescimento econômico e da geração de emprego e renda, havendo estudos que sugerem estarmos na era do empreendedorismo (AIDAR, 2007; DORNELAS, 2008; MURPHY; LIAO; WELSH, 2006). Mais do que mudanças nas formas de organização da produção, pode-se identificar novas formas de percepção acerca do trabalho e dos valores a atrelados a ele, onde "a valorização do trabalho autônomo empreendedor reinterpreta (...) o trabalho informal, destacando seu potencial criador vinculado à predisposiçãoi individual ao risco e à inovação" (LIMA, 2010, p.159). Como empreender passa a ser compreendido como imprescindível para inovar, aumentar a produtividade e melhorar os negócios, pode-se argumentar que o homo economicus cede espaço ao homo entreprenaurus, configurando um quadro em que um modelo específico de capitalismo empreendedor é anunciado (BOAVA; MACEDO, 2009; SCHRAMM; LITAN, 2008).

No contexto empresarial, as discussões giram em torno do empreendedorismo como meio de inserção estratégica em um mercado global imprevisível, turbulento e competitivo (LUMPKUN; DESS, 1996; MINTZBERG, 1973), o que torna fundamental o desenvolvimeno de atitudes e culturas empreendedoras nos indivíduos e organizações (SANTOS; EISENHARDT, 2009; GARTNER, 1989; KETS de VRIES, 1977). Esse processo redefiniria a atuação das organizações, enfatizando a inovação, a busca e identificação de oportunidades, o trabalho criativo, a integração da organização e dos processos de trabalho, a eliminação de barreiras internas de comunicação, e a reflexão sistemática sobre riscos na tomada de decisão (BYGRAVE; HOFER, 1991). Todavia, o empreendedorismo tem sido relativamente pouco investigado, e menos ainda de forma crítica (OGBOR, 2000; GARUD; HARDY; MAGUIRE, 2007; KHAN; MUNIR; WILLMOTT, 2007), o que em parte se deve às grandes divergências quanto à temática.

Sob uma perspectiva individual, predominam os trabalhos que identificam as características mais relevantes dos empreendedores, na maior parte dos casos, as mesmas: a) valores e cultura do empreendedorismo adquiridos mediante um modelo empreendedor na juventude; b) tenacidade e capacidade de tolerar ambiguidades e incertezas; c) experiência em negócios; d) diferenciação; e) intuição; f) envolvimento; g) assunção de riscos moderados; h) visão; i) imaginação; j) liderança; k) busca de resultados; l) capacidade de trabalho em rede; m) criação de um sistema próprio de relações com os empregados; n) controle do comportamento das pessoas ao seu redor; e o) aprendizagem por meio de seus próprios padrões. 
Quanto ao foco gerencial, a maioria dos estudos aborda habilidades e competências empreendedoras e sua relação com o espaço organizacional. Há estudos sobre o empreendedorismo institucional (MUTCH, 2007), empreendedores como produtos organizacionais (AUDIA; RIDER, 2005), empreendedorismo social (PARKINSON; HOWORTH, 2007), coletivo e sustentável e o intra-empreendedorismo. Várias correntes teóricas aparecem, discutindo o empreendedorismo como: a) fomento tecnológico, criando, desenvolvendo e gerenciando empresas emergentes; b) gestão (difusão da prática da gestão empreendedora); e c) estratégia de desenvolvimento local integrado e sustentável pelo desenvolvimento de pequenas e médias empresas (MURPHY, 2009).

Com o tempo as pesquisas mudaram da análise da figura do empreendedor para o negócio por ele criado, tratando de temas mais estratégicos, como a criação e o desempenho de novos empreendimentos (SANTOS; EISENHARDT, 2009), empreendimentos dentro de universidades, as estratégias iniciais e as barreiras à entrada no negócio, o papel do capitalista de risco e seus critérios de decisão, análises de estratégias de crescimento (GREGOIRE; DÉRY; BÉCHARD, 2001) e de performance empresarial. A inovação continua em foco com definições que privilegiam oportunidades de investimento, de produto e de negócios (KRUGER; BRAZEAL, 1994) ou a criação de empresas (GARTNER, 1989).

Pelas distintas concepções, o empreendedorismo pode constituir um rótulo vazio, "uma palavra que pode significar tudo e nada, uma palavra que não tem um significado intrínseco, não tem (...) relação com nenhum dos objetos com os quais é normalmente associada que remete a vários pontos sem chegar efetivamente a nenhum deles" (WALKER, 1989, p.164). Tal condição é conveniente para naturalizar processos, já que o conceito pode assumir diferentes significados dependendo apenas da forma escolhida de apropriação de seus sentidos. Não por acaso identifica-se um processo de naturalização, universalização e descontextualização das ideias de empreendedorismo, sendo privilegiadas as abordagens com consequências positivas do processo de empreender para os indivíduos, organizações e países (COSTA; BARROS; CARVALHO, 2011).

Pouco é discutido acerca das relações de poder inerentes aos desdobramentos do discurso empreendedor, como da dita convergência entre interesses empresariais e individuais nas relações de trabalho, do tipo de trabalhador que o empreendedorismo privilegia, do contexto histórico profissional da maioria dos empreendedores ou da sua vocação e treinamento. Tampouco se discute a quem interessa a disseminação de um modelo cujo empreendedor é capitalista, ocidental, branco, masculino, heterossexual e euro-norte-americano - tido como certo e como padrão a ser copiado por todos os demais (McLAREN, 1997; ESSERS; BENSCHOP, 2007). 
Assumimos que o discurso, ao produzir visões de mundo hegemônicas que enquadram, moldam e constituem as relações entre os atores sociais, permite compreender melhor o empreendedorismo e seus discursos constituintes (HARDY, 2001; GRANT; KEENOY; OSWICK, 2001). No contexto atual, onde a desregulamentação produtiva redefine as relações entre capital e trabalho e desqualifica leituras alternativas sobre o mundo (CARDOSO, 2000), a dimensão humana tem constituído um componente de produção e reprodução econômica - e ideológica (LEITCH; PALMER, 2010; BOJE; OSWICK; FORD, 2004). Para isso, analisamos a esfera educacional a partir da observação de que a sedimentação de parte da ideologia do empreendedorismo reside nos processos de formação superior na área de administração.

No Brasil, o empreendedorismo integra os currículos de cursos superiores por orientações das diretrizes curriculares nacionais, que sugerem um perfil para o administrador que desenvolva, entre outros pontos, uma capacidade empreendedora e crítica. Além das disciplinas ligadas ao tema, as universidades incentivam as empresas juniores, constituídas como espaços para a prática empreendedora à medida que aproximam práticas acadêmicas e de mercado. Nossa questão central foi identificar que ordens de discurso emergem do discurso sobre o empreendedorismo nas empresas juniores brasileiras, assumindo que as relações interdiscursivas entre os seus discursos sobre o tema contribuem, ideologicamente, para a eleição da empresa capitalista contemporânea como único modelo possível de geração de riqueza na sociedade.

\section{Empreendededorismo e Ideologia}

Diante das crises iniciadas nos anos 1970, um conjunto de políticas elaboradas no início dos anos 1980 pelos países centrais, que diagnosticavam a estagnação econômica do período como excesso de regulamentações (o Consenso de Washington), modificavam "o futuro da economia mundial, as políticas de desenvolvimento e especificamente o papel do Estado na economia" (SANTOS, 2002, p.33). Suas três principais inovações institucionais foram: restrições à regulação estatal da economia, a emergência de novos direitos de propriedade internacional para investidores estrangeiros, inventores e criadores de inovações, e a subordinação dos Estados nacionais às agências multilaterais. $\mathrm{O}$ caminho adotado foi a desregulamentação das economias mediante privatizações, liberalização do mercado e do sistema financeiro, abertura das economias dos países para o mercado externo, políticas de flexibilização laboral e de ajuste fiscal (CARDOSO, 2000; CHOMSKY, 2011).

Neste contexto, a conduta exemplar passa a ser a conduta do indivíduo empreendedor e o discurso do empreendedorismo passa a ser vinculado às reformas nos países da América Latina (LIMA, 2010). O 
empreendedor, no entanto, deixa de apresentar um perfil raro de indivíduo que inicia a mudança (SCHUMPETER, 1982; SOMBART, 1946), já que o neoliberalismo sugere que todos sejam empreendedores (KRUGER; BRAZEAL, 1994), um fenômeno de massa, o que torna o empreendedorismo simultaneamente a atitude de um povo que busca o desenvolvimento socioeconômico de seu país e uma nova ética empresarial do trabalho: "sinônimo de flexibilidade, abrange desde consultores altamente qualificados, com contratos temporários e/ou por projetos (...) chegando até os trabalhadores em atividades precárias como ambulantes, camelôs e outros (...)" (LIMA, 2010, p. 161).

Essa nova ética do trabalho pressupõe uma estreita ligação entre indivíduo e empresa, o que pode ser verificado em abordagens sobre o empreendedorismo em que são transferidas para as empresas características do empreendedor, como em Lumpkin e Dess (1996) cujas dimensões do seu modelo (autonomia, capacidade de inovação, capacidade de assumir riscos, capacidade de agir proativamente e competitividade agressiva) se referem não aos empreendedores, mas à orientação empreendedora das organizações. Apesar de adquirido maior visibilidade nas duas últimas décadas, contudo, esta exaltação de um "espírito" empreendedor não é algo novo, estando alinhada aos pressupostos da reformulação neoliberal da economia política contemporânea, na qual o capitalismo produz um repertório de explicação da realidade que toma o executivo capitalista como matriz de conduta a ser disseminada pela sociedade inteira (ARMSTRONG, 2005).

Tal perspectiva intensifica a dedicação da vida do homem contemporâneo ao ganho, reduzindo-o à dimensão do interesse e lhe incorporando a lógica do capital "como se ela fosse (...) o fundamento último da própria vida humana em sociedade" (SANTOS, 2002, p.23). Nessa racionalidade, para que uma sociedade baseada em livre mercado produza mais riqueza, são necessários indivíduos quem criem e aproveitem oportunidades, melhorem processos e inventem negócios, sempre com uma contemporânea ênfase no individualismo e no ganho próprio (BORGES, 2000). Quase todas as pessoas podem ser empreendedores: o fundador de uma organização, o gerente de sua própria empresa, o líder que inova na empresa de outrem, ou qualquer pessoa que tome uma iniciativa estratégica em uma organização - o empreendedor interno (MINTZBERG; AHLANTRAND; LAMPEL, 1998).

A busca do ganho constitui mais do que uma obrigação e o indivíduo - sujeito econômico capitalista por excelência - torna-se empreendedor de sua própria vida, o que, conforme Gaulejac (2007), o transforma em um capital que convém tornar produtivo, de forma que a incorporação e disseminação de "um espírito que oferece perspectivas sedutoras e estimulantes de vida dando ao mesmo tempo garantias de segurança e razões morais para se fazer o que se faz" (BOLTANSKI; CHIAPELLO, 
2007, p. 58). Podem-se identificar mudanças ideológicas que acompanharam as transformações do capitalismo para justificar o engajamento necessário - em especial em um modelo capitalista significativamente custoso em termos humanos - para o funcionamento do sistema como um todo.

Conforme Harvey (1991), duas áreas de dificuldades precisam ser negociadas e justificadas com sucesso para que um sistema econômico capitalista seja viável: a) as provenientes das qualidades anárquicas dos mercados de fixação de preços; e b) as oriundas da necessidade de exercer o controle sobre o emprego da força de trabalho. Quanto à segunda área, algumas premissas mostram-se fundamentais, em particular a da disciplina da força de trabalho. Já que aos indivíduos é transferida a responsabilidade pelas suas carreiras, a formação empreendedora lhes sugere que inserção profissional equivale a consentir iniciativas empresariais pró-flexibilizaçao do trabalho. À medida que se tornam apenas individuais as questões profissionais, estas passam a ser definidas conforme a capacidade dos indivíduos em competir (e vencer), enfraquecendo o coletivo ao instalar uma lógica darwiniana de todos contra todos, em que só se beneficiam as empresas, em detrimento da sociedade.

Cabe ressaltar que esta figura do empreendedor não possui vínculos com as consequências dos princípios neoliberais. McChesney (2002) destaca que tais políticas geram crescimento da desigualdade econômica e social, com aumento da pobreza absoluta entre as nações e povos mais atrasados, e enriquecimento acelerado dos já ricos, um ambiente global catastrófico associado a uma economia global instável. No nível profissional, naturaliza-se que o profissional contemporâneo é uma unidade econômica autônoma inserida num quadro competitivo, que deve se considerar um negócio, tornando o empreendedorismo uma ideologia do "novo espírito" do atual capitalismo, onde um conjunto de crenças dirige, justifica e legitima o comprometimento dos indivíduos com o sistema (BOLTANSKI; CHIAPELLO, 2007). Com a flexibilização das relações de trabalho, o indivíduo com livre iniciativa para abrir negócios tem sua importância ressignificada para atuar também, por meio de tênues vínculos empregatícios, como empreendedor organizacional, coletivo e intra-empreendedor, o que pode ser auxiliado pelos processos educacionais.

\section{O empreendedorismo e as empresas juniores}

A ideia da empresa junior (EJ) surgiu em 1967 na França, na L'Ecole Supériore des Sciences Economiques et Commerciales de Paris para oferecer aos universitários maior qualificação para o mercado pela junção de teoria e prática profissionais, tendo sido criada em 1990 a Confederação 
Europeia de Empresas Juniores. No Brasil, embora a primeira empresa tenha sido criada no curso de Administração nos anos 1980, o fenômeno já se estendeu a outros cursos, como Computação, Engenharia, Psicologia e Turismo.

As EJ são associações civis com fins educacionais, sem fins lucrativos, constituídas e gerenciadas no âmbito da universidade por estudantes, e que prestam serviços para a sociedade em geral sob supervisão de profissionais especializados. Promovem atividades sob a forma de projetos de consultoria estebelecendo laços entre sociedade, empresas e universidade, possuindo uma configuração semelhante: assembleia geral, conselho administrativo, diretoria executiva, conselho consultivo e conselho fiscal.

Possuem três características essenciais: são organizações com gestão autônoma e responsáveis pelos seus atos; a receita proveniente dos projetos desenvolvidos deve ser reinvestida na empresa, não podendo ser distribuída entre seus membros; e é necessariamente apartidária, sem envolvimento com partidos políticos. É seu papel promover o: a) desenvolvimento técnico e acadêmico de seus associados; b) desenvolvimento econômico e social da comunidade por meio de suas atividades; c) espírito empreendedor de seus associados; d) contato dos estudantes com o mercado de trabalho; e e) desenvolvimento pessoal e profissional de seus associados.

Inseridas em um movimento denominado Movimento Empresa Junior (MEJ) e seguindo o modelo importado europeu, as EJs brasileiras contam com uma organização representativa nacional - a Confederação Brasileira de Empresas Juniores (BrasilJunior) - e com Federações Estaduais. A BrasilJunior tem como finalidade representar as empresas juniores em nível nacional e desenvolver o MEJ como agente de educação empresarial e gerador de novos negócios. Esta organização promove reuniões periódicas, encontros nacionais e confere uma "qualidade mínima" para as práticas por meio de um selo de certificação: o Selo BrasilJunior.

Além de constituírem verdadeiros laboratórios de aprendizagem, as definições do Ministério da Educação explicam, parcialmente, a quantidade de EJs no Brasil (são mais de 600), já que valorizam a articulação entre teoria e prática, avaliando positivamente as instituições de ensino superior que mantem tais organizações funcionando. $\mathrm{O}$ tempo médio de permanência dos estudantes nessas organizações é de dois anos, período em que, ao buscar soluções de forma criativa, se capacitam para a liderança empresarial de forma mais efetiva do que em estágios convencionais, o que culmina com a sua transformação em empreendedores.

\section{Metodologia}


Estudo qualitativo, a coleta de dados foi realizada mediante entrevistas individuais em profundidade com estudantes e professores participantes de seis empresas juniores de instituições do ensino superior no Rio de Janeiro, Brasil. As entrevistas foram baseadas em um mesmo tópico guia (GASKELL, 2000) com perguntas não estruturadas, tendo sido integralmente gravadas e transcritas. A coleta de dados foi realizada em dois momentos, sendo o primeiro entre 2007 e 2008, e o segundo durante o ano de 2010, tendo sido realizadas 60 entrevistas no total. Os insumos textuais foram tratados por meio da análise crítica do discurso. A perspectiva utilizada foi a de Norman Fairclough (2001; 2003), cuja teoria social do discurso pressupõe a utilização de um esquema tridimensional de análise no qual o evento discursivo é examinado, simultaneamente, como: a) um pedaço de texto, o que demanda a análise do seu conteúdo, da sua estrutura e do seu significado; b) uma instância de prática discursiva, pressupondo análise da interação discursiva usada para comunicar significados e crenças; e c) uma instância de prática social, considerando o contexto social no qual os discursos são construídos.

Optamos por essa abordagem assumindo que discurso e poder constituem as relações sociais por meio de um processo de articulação e rearticulação (CHOULIARAKI; FAIRCLOUGH, 2010), contribuindo as formações discursivas tanto para reproduzir a sociedade (identidades sociais, relações sociais, sistemas de conhecimento e crença) como para transformá-la (BOJE; OSWICK; NORD, 2004). É neste sentido que as ordens de discurso constituem a totalidade das práticas discursivas dentro de uma instituição ou sociedade e suas articulações (e lutas de poder), sendo fundamentais para qualquer formação discursiva (FAIRCLOUGH, 2001). A articulação e a rearticulação de ordens de discursos podem ser entendidas como um marco delimitador na luta hegêmonica. Conforme Fairclough (2001), o conceito de hegemonia vincula-se às ordens de discurso por refletir o poder de um grupo sobre a sociedade sempre em aliança com outras forças sociais. Por isso, há um constante embate para construir, manter ou romper estas alianças e suas respectivas e inerentes relações de dominação. Além disso, a prática discursiva (produção, distribuição e consumo de textos) contribui para a reprodução ou transformação não apenas da ordem de discurso existente, mas também das próprias relações sociais, como discutiremos adiante.

\section{Análise e discussão dos dados}

A análise permitiu identificar um conjunto de objetos discursivos associados ao empreendedorismo. Estes foram categorizados, em um primeiro momento de forma separada, o que tornou possível revelar formações discursivas. Em um segundo momento, as formações discursivas foram analisadas em suas intertextualidades, tanto no que diz 
respeito à intertextualidade manifesta quanto à constituída, o que permitiu enxergar ordens de discursos. Foram identificados os objetos discursivos: 1) sucesso acadêmico como inserção no mercado; 2) laboratório do mercado; 3) remuneração financeira dos membros; 4) proatividade na busca de conhecimento; 5) compartilhando experiências; 6) novas formas de fazer; 7) iniciativa e acabativa; 8) adicionando valor ao currículo; 9) trampolim para o mercado; 10) aquisição de status; 11) desenvolvendo atividades ímpares; 12) educação formal; 13) incorporando temas da moda; 14) superação individual e crescimento profissional; 15) escravo junior; 16) geração e expansão de negócios; 17) empreendedorempresário; 18) celeiro de empreendedores; 19) potencializando oportunidades; 20) formação de redes sociais e redes de trabalho; 21) exemplaridade familiar; 22) exemplaridade dos executivos de sucesso; e 23) exemplaridade dos ex-membros.

\section{As formações discursivas}

A intertextualidade levou ao agrupamento dos objetos discursivos em sete formações discursivas: a) articulação universidade-mercado; b) espírito empreendedor; c) diferenciação no mercado; d) aprender fazendo; e) geração de riquezas; f) empreendedor como produto organizacional; g) modelos sociais de empreendedores, os quais serão analisados em seguida.

a) Articulação universidade-mercado

Nessa formação discursiva identificamos um movimento de articulação entre práticas acadêmicas e de mercado, sendo este colocado como a principal fonte de riqueza, de crescimento e de realização pessoal e profissional. Os três objetos discursivos que a compõem são: "sucesso acadêmico como inserção no mercado", "laboratório do mercado" e "remuneração financeira dos membros".

No primeiro objeto discursivo, "sucesso acadêmico vinculado à inserção no mercado", sistematicamente emergem palavras como empreendedorismo, aplicabilidade, prática, inserção no mercado de trabalho e sucesso. Nas entrevistas, a passagem por uma empresa junior é relevante já que a prática (nas empresas juniores) prepondera sobre a teoria (nas salas de aula), tornando possível o sucesso. Os professores, ao recomendarem a teoria aos estudantes para solucionar problemas cotidianos na empresa junior, sugerem ser a inserção profissional o principal objetivo da experiência universitária, o parâmetro do seu sucesso.

O segundo objeto discursivo trata da formação comprometida com as expectativas empresariais, sendo a empresa junior um "laboratório do 
mercado", por antecipar a prática do que posteriormente será feito no mercado de trabalho. O discurso sobre a experiência adquirida nas práticas das empresas juniores a associa, de forma recorrente, ao aprendizado nos mesmos "cargos" no mercado, como se os estudantes já assumissem as mesmas atribuições e responsabilidades de profissionais estabelecidos.

O objeto discursivo "remuneração financeira dos membros" é polêmico, dividindo posições entre os empresários juniores e explicitando incongruências entre mercado e ensino, pois como pode existir um laboratório do mercado sem remuneração? Há entrevistas contra a remuneração, baseadas em princípios do $\mathrm{MEJ}$, como voluntariado e aquisição de conhecimento, assim como depoimentos que sustentam que se a empresa junior é para ser uma empresa de mercado, que o seja efetivamente, inclusive remunerando seus membros, contradizendo alguns dos valores básicos do movimento.

Os discursos analisados apontam uma estreita ligação entre indivíduo e empresa também no ambiente educacional. A decorrência é uma problemática noção de que ensino eficiente forma profissionais estritamente para o mercado, o que implica comprometimento apenas com os resultados empresariais em detrimento da sociedade, uma instrumentalização radical da educação superior.

b) Espírito empreendedor

Nesta formação discursiva os discursos consideram a existência de um espírito empreendedor nas práticas das empresas juniores e a necessidade de desenvolvimento mediante atitudes inovadoras. Identificamos princípios e características empreendedoras que norteiam o agir específico do indivíduo no mundo em quatro objetos discursivos: "proatividade em busca do conhecimento", "compartilhando experiências", "novas formas de fazer" e "iniciativa e 'acabativa'". O primeiro objeto discursivo, "proatividade em relação à busca de conhecimento", aparece em quase todas as entrevistas. A iniciativa de buscar conhecimento é atribuída ao membro logo que ele ingressa na empresa junior nos programas de trainee. Essa proatividade é importante porque prepara para o mercado de trabalho, entendido como o espaço onde é "cada um por si", sentimento reforçado pelas dificuldades encontradas em comprometer os professores com os projetos desenvolvidos, levando-os a outras fontes de informação.

Quanto ao segundo objeto discursivo "compartilhando experiências", apesar de ser algo individual, adquirir conhecimento não se relaciona apenas à sala de aula, sendo mais comum a troca de experiências com pares, membros de outras empresas juniores, e aconselhamento com exmembros. Por um lado, o compartilhamento é possível em função de estas organizações não adotarem a mesma noção de competitividade do 
mercado. Porém, o compartilhamento de informações não é pleno, especialmente quanto aos serviços oferecidos, sugerindo que há concorrência - tanto entre as empresas juniores quanto na relação entre estas e os professores - o que desvirtua a concepção do MEJ.

O espírito empreendedor é construído discursivamente atrelado à ideia de empresário junior, tanto no que se refere à criação quanto na execução de atividades, o que se manifesta no objeto discursivo "novas formas de fazer": o empreendedor percebe oportunidades onde ninguém as enxerga e as aproveita, inclusive dentro da empresa junior, embora haja limites para a atuação inovadora. Em alguns depoimentos, emerge o discurso que opõe a inquietude e a busca de inovação dos empreendedores ao aborrecimento com a rotina tão logo iniciam seus negócios, o que os leva a investir em novos projetos. O empreendedor, todavia, não é somente quem inicia um novo negócio e inova sempre, mas quem realiza, implementa e obtém sucesso. Como desdobramento, o quarto objeto discursivo "iniciativa e 'acabativa'", significa que ter ideias não é suficiente, é preciso concretizá-las.

Essa formação discursiva encerra discursos alinhados a uma sociedade baseada no livre mercado e aos seus valores demandados, implicando um perfil profissional que, além de empreendedor, seja também adaptável, comprometido, autônomo e ambicioso.

c) Diferenciação no mercado

É importante para cada indivíduo se destacar dos demais em um contexto de competição, considerada saudável e normal. A formação discursiva, "diferenciação no mercado", identifica os diferenciais enunciados pelos participantes por serem membros de uma empresa junior, abrangendo quatro objetos discursivos: "adicionando valor ao currículo", "trampolim para o mercado", "aquisição de status", e "desenvolvimento de atividades ímpares". Distinguir-se dos demais, embora não seja imprescindível nas empresas juniores, é fundamental no mercado. O primeiro objeto discursivo "adicionando valor ao currículo" trata-se de algo almejado pelos estudantes e endossado pelos professores. Paa eles, apenas paarticipar da empresa junior não é suficiente, sendo necessário adquirir certa "bagagem" considerada adequada pelo mercado.

Nesse sentido, a empresa junior é compreendida como um "trampolim para o mercado" (segundo objeto discursivo), contribuindo para que seus membros possam assumir posições relevantes nas empresas mais disputadas no mercado de trabalho. Esse processo pode ou não vir acompanhado do terceiro objeto discursivo, "aquisição de status", que diferencia os membros das empresas juniores dos demais estudantes por que eles estariam aptos a "desenvolver atividades ímpares" (quarto objeto discursivo), uma vez que as atividades realizadas são importantes, 
diferenciadas e semelhantes às do mercado, não sendo possíveis de serem vivenciadas nos programas estágio convencionais.

Estes quatro objetos discursivos corroboram diferenças percebidas pelos entrevistados por atuarem em uma empresa junior. As atividades são entendidas como próximas das praticadas pelos profissionais já atuantes no mercado, o que torna possível ao estudante, ainda dentro de um espaço acadêmico, participar de ações e ocupar cargos que nenhum programa de estágio poderia oferecer.

d) Aprender fazendo

Para os estudantes entrevistados, a discussão em torno do empreendedor e do empreendedorismo relativiza a importância da educação formal, uma vez que, em seus discursos, os empreendedores de sucesso podem prescindir desse tipo de conhecimento "metendo a mão na massa". A formação discursiva "aprender fazendo", assim, associa o aprendizado à prática. Quatro objetos discursivos integram essa formação discursiva: "educação formal", "incorporando temas da moda", "superação individual e crescimento profissional" e "escravo junior".

Enfatizar a prática não implica os estudantes desprezarem a universidade (tomada como o espaço da teoria), mas que consideram que aprender fazendo é inerente ao empreendedor, o que faz da educação formal algo eventualmente irrelevante. Esse raciocínio se estende ao cotidiano, pois da mesma forma que os empreendedores de sucesso podem prescindir do conhecimento acadêmico, já que a prática lhes ensina, os estudantes questionam a aplicabilidade das disciplinas oferecidas, sendo inclusive o próprio empreendedorismo tomado como algo difícil de ser ensinado. Nesse sentido, o que não pode ser imediatamente aplicado não interessa, o que confunde educação superior com educação técnica, dirigida estritamente para a aplicação.

O segundo objeto discursivo "incorporando temas da moda" diz respeito à utilização da mídia de negócios para aquisição de conhecimento. Apesar de as revistas de negócios serem dirigidas a profissionais já estabelecidos, são citadas como fontes de informação para as práticas dos empresários juniores. Ao mesmo tempo, quando indagados se as revistas os ajudam a resolver problemas na empresa junior, não as reconhecem como suporte, o que sugere baixa capacidade de abstração a partir da consulta à mídia de negócios. Outro ponto importante é um explícito e frequente uso de termos midiáticos nas falas e descrições das práticas das empresas juniores, como benchmarking, proatividade, coaching etc.

De acordo com os depoimentos, a empresa junior, espaço da prática, proporciona o amadurecimento mediante o terceiro objeto discursivo, "superação individual e crescimento profissional". Essa ideia também 
aparece nas entrevistas dos professores, que diferenciam o comprometimento e a seriedade dos empresários juniores do comportamento dos demais estudantes. Também emerge dos depoimentos a ideia de que o trabalho na empresa junior é exaustivo, ainda que as recompensas quanto ao crescimento profissional dos membros sejam entendidas como grandes, o que leva a alguns dos entrevistados a mencionarem, com ironia, que o empresário junior é muitas vezes um "escravo junior" (quarto objeto discursivo), por se sacrificar, como muito trabalho, e nenhuma remuneração. $\mathrm{O}$ sacrifício também inclui o afastamento dos amigos e da família e, em alguns casos, abrir mão de relacionamentos afetivos e de hobbies.

A articulação entre os quatro objetos discursivos da formação discursiva "aprender fazendo" privilegia a prática em detrimento da vida acadêmica, uma vez que o empreendedor pode prescindir da teoria, sem, contudo, podê-lo fazer quanto à prática profissional. Negligenciar a teoria pode levar à transformação de indivíduos em sujeitos-mercadorias, sempre submissos ao mercado de trabalho. Atuar praticamente em algo considerado prioritário, combinado ao comprometimento dos membros das empresas juniores, não faz da "escravidão junior" um problema, sendo o sacrifício parte do processo.

e) Geração de riquezas

A quinta formação discursiva, "geração de riquezas", sugere que o empreendedor possui a função social de converter oportunidades em resultados econômicos, abrangendo três objetos discursivos: "geração e expansão de negócios", "empreendedor-empresário" e "celeiro de empreendedores". Para os entrevistados, são empreendedores os que impulsionam o capitalismo mediante a "geração e a expansão de negócios" por meio de novos bens de consumo e métodos inovadores de gestão e produção. Tais indivíduos são caracterizados como proprietários ou empregados que possuem a função social de identificar oportunidades e convertê-las em valores econômicos, desempenhando um papel fundamental de expansão ou, principalmente, de geração de negócios. A geração de negócios também pode ocorrer mediante os projetos de consultoria desenvolvidos pelos empresários juniores junto aos seus principais clientes.

Tanto os estudantes quanto os professores entrevistados tiveram dificuldades em identificar empreendedores em áreas que não a de negócios, vinculando o "empreendedor ao empresário" (segundo objeto discursivo) e à sua identidade no espaço organizacional de gestão, em particular no da empresa junior. Como desdobramento, o terceiro objeto discursivo se refere à empresa junior como um "celeiro de pessoas empreendedoras" que atuarão no mercado ou abrirão empresas, o que 
implica a prática empresarial ser discursivamente associada à ideia de empreendedor e empreendedorismo.

Os três objetos discursivos desta formação discursiva ("geração e expansão de negócios", "empreendedor-empresário" e "celeiro de empreendedores") se articulam em torno da formulação de que o empreendedor converte oportunidades em resultados econômicos, incorporando o papel de agente social de expansão dos negócios, contribuindo indiretamente para o desenvolvimento da sociedade.

\section{f) Empreendedor como produto organizacional}

A formação discursiva "empreendedor como produto organizacional" agrupa objetos discursivos que identificam a inserção no mercado de trabalho a partir da experiência profissional em uma grande empresa, "potencializando oportunidades" e "formação de redes sociais e redes de trabalho". Apesar de a empresa junior ser percebida como uma organização que potencializa a emergência de futuros empreendedores, os discursos enunciam que a participação como empregado de uma grande empresa leva a um processo de aprendizado mais efetivo, "potencializando oportunidades" (primeio objeto discursivo) mediante a ampliação das possibilidades de inserção profissional como trabalhador empreendedor ou dono do seu próprio negócio. Assim, a abertura de um negócio deve ser precedida pela aquisição de experiência em organizações maiores, mais estruturadas, com mais legitimidade e participação no mercado. Tal premissa corrobora os argumentos de Sorenson e Audia (2000), de que são as organizações que criam oportunidades para que as pessoas desenvolvam confiança em sua capacidade de abrir e administrar uma empresa.

A interação entre membros de uma mesma empresa junior, empresários juniores de empresas juniores distintas diferentes e exempresários juniores ajuda a formar "redes sociais e redes de trabalho", o segundo objeto discursivo, que facilitam a mobilização de recursos e a inserção profissional. Conforme Brittain e Freeman (1986), os empreendedores contam com seus relacionamentos sociais para mobilizar os recursos para a própria empresa, tanto financeiramente quanto no que se refere a equipes, o que significa lidar com pessoas bem relacionadas e de sucesso na área em que o empreendedor espera abrir seu negócio.

$\mathrm{Na}$ formação discursiva "empreendedor como produto organizacional" os depoimentos enfatizam a importância do papel empresa na experiência profissional dos empreendedores, o que pode se dar tanto no nível da expertise adquirida ao longo de distintas atividades produtivas quanto no nível social, uma vez que laços sociais com indivíduos bem sucedidos podem significar contribuições no processo de abertura de negócios. 
g) Modelos sociais de empreendedores

$\mathrm{Na}$ última formação discursiva, "Modelos sociais de empreendedores", os entrevistados se inspiraram em exemplos de empreendedores de sucesso, tendo sido contemplados três objetos discursivos: "a exemplaridade familiar", "a exemplaridade dos executivos de sucesso" e "a exemplaridade dos ex-membros". O primeiro objeto discursivo se refere à "exemplaridade familiar". Para muitos dos entrevistados, a qualificação para o sucesso parece ser potencializada pelo ambiente familiar, uma vez que os primeiros exemplos vem da família, incluindo personagens que tiveram diferentes negócios, não necessariamente formais, histórias de superação, perseverança e sucesso, recorrentemente.

A "exemplaridade dos executivos de sucesso" constitui o segundo objeto discursivo.

Quando perguntados sobre qual o primeiro exemplo de empreendedor que lhes vinha à mente, os nomes lembrados foram quase sempre de empreendedores de sucesso assíduos na mídia, como Bill Gates e Steve Jobs e Donald Trump. O terceiro objeto discursivo diz respeito à "exemplaridade do ex-membro". Da mesma forma que nos dois objetos discursivos anteriores, quando perguntados sobre um exemplo de empreendedor, o caso lembrado referia-se à história de um membro ou exmembro de empresa junior considerado um profissional de sucesso.

Os vínculos dos ex-membros são descritos com palavras fortes como eternos, de sangue, DNA, paixão, sendo considerados pelos entrevistados como algo que deixa marcas para sempre, o que é reforçado pelo retorno dos ex-membros à sua antiga empresa junior, sempre dispostos a ajudar a estruturar e a reestruturar as práticas profissionais, o que normalmente fazem por meio de conselhos com base em suas próprias vivências. Todas as empresas juniores pesquisadas convocam seus ex-membros para serem palestrantes em eventos onde não só esperam estimular os atuais membros como também captar novos integrantes, reforçando o discurso do sucesso no mercado pela experiência de ter sido um empresário junior.

A ação dos ex-membros se estende a verdadeiras intervenções em alguns casos, quando não aprovam a situação em que se encontra a empresa junior e cobram melhores resultados da equipe, sentindo-se pessoalmente incomodados quando as coisas não vão bem. No caso de algumas empresas juniores, esse vínculo é tão forte que os ex-membros mais ativos são nomeados de forma diferente, como alumini. Os exmembros também participam dos conselhos deliberativos que, entre outras funções, auxiliam tanto a seleção e a eleição dos presidentes quanto na manutenção de uma "cultura organizacional" adequada. 
Os três objetos discursivos remetem à questão dos exemplos empreendedores que podem ser oriundos da família, da mídia ou do da própria história das empresas juniores. De certa forma, verifica-se a massificação do conceito, uma vez que os empreendedores não são mais entendidos como indivíduos únicos e raros, sendo algo relativamente comum (SANTOS, 2002) - pelo menos os de sucesso - principalmente se já tiverem passado pela organização.

\section{O empreendedorismo como ideologia e prática social}

As formações discursivas são entendidas, em uma dada formação ideológica, como o que pode e o que deve ser dito em determinado tempo e espaço (FAIRCLOUGH, 2001). Essas regiões do dizível refletem diferenças ideológicas, isto é, as posições dos sujeitos em lugares sociais representados e desigualmente acessíveis. Nessa seção procuramos examinar as intertextualidades constituídas (ou interdiscursividade) entre as formações discursivas acerca do empreendedor e do empreendedorismo das empresas juniores. Ao serem reconhecidas as intertextualidades é possível também identificar práticas discursivas que, inseridas em práticas sociais, possibilitaram explicitar as ordens de discursos.

\section{a) Convergências}

As formações discursivas inserem-se em um contexto que valoriza um tipo específico de empreendedor (empresário ou empregado) que converte seus objetivos individuais e sociais em estratégias organizacionais, levando as demandas das empresas a ditar as prioridades, os valores e princípios que regem as relações de trabalho. Nesse sentido, a primeira convergência identificada nos discursos acerca do empreendedor e do empreendedorismo aparece nos objetos discursivos "geração e expansão dos negócios", "empreendedor-empresário" e "celeiro de empreendedores".

Tais discursos compreendem o empreendedorismo como um fenômeno de massa em que todos podem, por meio deste, realizar-se pessoal e profissionalmente. Todos podem ser empreendedores bastando, para que isso ocorra, duas condições: 1) assumir o indivíduo como alguém autônomo e que possui as características consideradas "adequadas"; e 2) existir um contexto socioeconômico inerentemente de livre mercado. Isso contribui para que o indivíduo seja empreendedor em tempo integral, o que deve ser uma atitude assumida por todos por promover o crescimento e o desenvolvimento socioeconômico dos países.

Uma segunda convergência surge como desdobramento da primeira e refere-se ao distanciamento entre ensino formal e prática profissional. Já 
que todos podem empreender, bastando para isso o atendimento de algumas condições, a educação formal perde a sua relevância na formação do indivíduo, já que não necessariamente forma empreendedores. Uma terceira convergência identificada está na categoria "espírito empreendedor", que destaca os mesmos princípios e as mesmas características empreendedoras atreladas ao indivíduo empreendedor e o seu agir no mundo dos negócios.

Uma quarta convergência é a estreita ligação entre indivíduo e empresa e um simultâneo processo de intensa valorização dos indivíduos que se realizam no trabalho, algo evidente no caso dos empreendedores que não conseguem parar de trabalhar, apesar da idade, da estabilidade financeira alcançada e dos sacrifícios inerentes ao processo. Em parte, isso se deve à importância atribuída aos modelos exemplares (familiares, midiáticos ou de sucesso) de empreendedores (quinta convergência), cujas histórias servem de estímulo ao associarem a figura do empreendedor a um herói - trabalhador ao extremo - que deve ser imitado.

Uma sexta convergência discursiva desloca o foco da ação inovadora empreendedora do indivíduo empreendedor para o empregado empreendedor. O espaço empresarial - em especial o da grande empresa é discursivamente construído como fundamental na formação do empreendedor e fomentador do empreendedorismo, que pode optar por continuar trabalhando como empregado (empreendedor interno) ou sair e abrir o seu próprio negócio. Mesmo quando as empresas juniores aparecem nos discursos como espaços de fomento do empreendedorismo, o discurso hegemônico é o de que os seus membros, antes de abrirem seus próprios negócios, devem trabalhar em uma grande empresa.

Isso, no entanto, não ocorre sem uma sétima convergência correlata, o discurso de que iniciativas empresariais pró-flexibilização do trabalho que transferem integralmente aos trabalhadores a responsabilidade por suas carreiras. Essas carreiras são definidas conforme a capacidade dos indivíduos em competir, e de, por fim, vencer. Os objetos discursivos "superação individual e crescimento profissional" e "proatividade na busca de conhecimento" convergem para valorizar o indivíduo inovador, adaptável e autônomo, isto é, com aversão a tudo que é rígido, rotineiro e seguro, em contraposição à necessária disponibilidade e entrega incondicional à rapidez, à mudança e ao risco. A oitava e última convergência se refere aos empreendedores como agentes sociais por definição mais adequados para impulsionar a máquina capitalista, potencializar os ganhos provenientes das inovações e alavancar países ao promover o desenvolvimento econômico.

b) Silêncios 
A análise dos silêncios é fundamental. É mediante seu reconhecimento que torna-se perceptível o que pode e o que não pode ser dito sobre algo (FAIRCLOUGH, 2001). O primeiro silêncio se refere ao lado negativo do empreendedor e do empreendedorismo. O vínculo do empreendedorismo com a atual ordem econômica mundial é um discurso natural e inexorável, cuja certeza pressupõe adesão. São silenciadas dúvidas pertinentes, como: o atual estágio do capitalismo não favorece a concentração do capital, as mega-fusões e os oligopólios? E não são estes fenômenos antagônicos ao livre mercado e à livre concorrência? $\mathrm{O}$ mesmo silêncio ocorre nos discursos dos estudantes, que silenciam sobre as reais dimensões do sacrifício pessoal pelas muitas horas de dedicação e trabalho necessárias para a entrega dos projetos dentro dos prazos, algo sempre suavizado por palavras como paixão, amor, dedicação, devoção.

Um segundo silêncio diz respeito ao fracasso, que somente adquire destaque quando o objetivo é articulá-lo discursivamente a alguma história de superação que culmina em sucesso. De forma recorrente, a imagem do herói, o empreendedor de sucesso, é contraposta à do antiherói: o mau empreendedor, lunático e fracassado. As construções discursivas empreendedor e empreendedorismo silenciam sobre os efeitos dos princípios neoliberais, o terceiro silêncio. Não são questionadas as implicações para as relações de trabalho contemporâneas da (re)produção da ideia de empreendedorismo. Naturaliza-se que o profissional contemporâneo seja uma unidade econômica autônoma inserida em um contexto competitivo e corporificado na imagem do "indivíduo S.A.", havendo silêncio sobre a precariedade das relações de trabalho, principalmente nas empresas juniores.

Um quarto silêncio diz respeito aos princípios que estão por trás da utilização de determinados conceitos sobre as ações empreendedoras, como harmonização (com expectativas das empresas), capacitação, treinamento e adequação (para o mercado). Assume-se como natural a conciliação entre interesses das empresas e interesses dos indivíduos que trabalham nas empresas. Nos discursos dos estudantes, isso se reflete na escolha destas palavras e não de outras para a composição discursiva.

Chama a atenção, como último silêncio, a não enunciação de relações de poder e de dominação presentes nas práticas empreendedoras das empresas juniores. Não são discutidas as hierarquias, as demissões (chamadas de desligamentos), o alto índice de rotatividade, a competição entre as empresas juniores por clientes etc. A questão da competição é um exemplo disso. Apesar da maioria dos entrevistados afirmarem que ela não existe, identificamos competição entre: estudantes para ingressar nessas organizações; estudantes e professores para ganhar novos clientes na forma de novos projetos; estudantes pelos cargos mais cobiçados; empresas juniores pelos clientes; e empresas juniores por espaço nas suas organizações representativas. 
c) As ordens de discurso

A análise das convergências e dos silêncios permitiu a identificação de três ordens de discurso: 1) o consenso acerca da centralidade da empresas; 2) a exemplaridade dos modelos empreendedores capitalistas neoliberais; e 3) a ausência de alternativas viáveis ao modelo capitalista contemporâneo. A primeira ordem de discurso se refere ao consenso sobre a centralidade da empresa na constituição do pensar e do agir do indivíduo no mundo. Ao mesmo tempo em que o discurso hegemônico proveniente e constituído pelas formações discursivas apregoa a busca de autonomia pelo indivíduo, isso não se desvincula do universo laboral, sendo a empresa central nesse processo. O empreendedor é um indivíduo autônomo, independente e proativo que, pela sua vocação, persegue oportunidades sem jamais se libertar da empresa.

Os empreendedores e seus discursos de sucesso conferem solidez ao discurso hegemônico por meio de recorrentes exemplos: do pai, da mãe, do colega de trabalho, do ex-membro de sua empresa junior e dos executivos de sucesso nas páginas das revistas de negócios. Tais formações discursivas constituem a segunda ordem de discurso: a exemplaridade dos modelos empreendedores capitalistas neoliberais. As formações discursivas produzem e reproduzem o discurso hegemônico, que usa modelos que legitimam um espírito capitalista empreendedor. É analtecido o empreendedor que sabe inovar, flexível, capaz de adaptar-se às novidades do mercado, às novas relações de trabalho, sempre de forma persistente, inequívoca, superando as barreiras e os obstáculos. Obstáculos e barreiras que, cabe ressaltar, são criados exatamente por estas mesmas empresas que buscam, de forma recorrente, o aumento em seus ganhos. Como afirma Meszaros (2000, p. 34), “os obstáculos reais enfrentados pelo trabalho (...) muito embora sintetizem as mais agressivas aspirações antitrabalho e políticas do neoliberalismo, pretendem ser tão recomendáveis, para toda criatura racional, como a maternidade e a torta de maça".

A terceira ordem de discurso se refere ao discurso que ignora alternativas ao capitalismo. $\mathrm{O}$ modelo neoliberal ocidental, consubstanciado nos discursos acerca das práticas empresariais empreendedoras discursivamente constitui consenso, o que permite que sua transposição para outras sociedades seja inevitável e benéfica. Em vista disso, críticas ao modelo são raras, pois "entre a lógica do lucro e o respeito pelas pessoas, as armas não são iguais (...) de um lado a 'dura realidade', à qual é preciso se adaptar; do outro, 'estados de alma' a qual é preciso "passar por cima'” (GAULEJAC, 2007, p.25). Como a hegemonia envolve complexas articulações de discursos que incorporam esforços de 
fixar significados de formas particulares sobre e contra outras possíveis articulações discursivas, o empreendedorismo se converte em "empreendedorismo capitalista": uma representação discursiva do mundo que justifica a adoção de uma abordagem instrumental e utilitarista para mediar, por meio do lucro, as relações entre os homens, e entre esses e o mundo do trabalho.

\section{Considerações finais}

O reconhecimento das ordens de discurso permite problematizar possíveis desdobramentos ideológicos nas relações entre educação e mercado de trabalho. Como consequência da primeira ordem de discurso - o consenso acerca da centralidade da empresa na constituição do pensar e do agir do indivíduo no mundo - o empreendedorismo adquire um papel primordial na sociedade: assegurar que cada indivíduo assuma, como suas, as metas de reprodução do sistema capitalista. Já que todos os indivíduos podem ser empreendedores, mesmo os que não o sejam de forma inata, podem desenvolver as habilidades e os comportamentos requeridos e adequados em espaços organizacionais específicos. Isso implica uma nova atitude frente à esfera produtiva, pois o profissional empreendedor passa a ser o gestor de sua carreira, o empresário de si mesmo. Como a esfera do trabalho será configurada em um capitalismo empreendedor que não abre mão de manter esse empreendedor nas empresas, mas lhe transfere o ônus dos rearranjos nas atuais relações de trabalho? Existiria tal possibilidade de conciliação entre o capital e o trabalho?

Como desdobramento da segunda ordem de discurso, a exemplaridade dos modelos empreendedores capitalistas neoliberais, alguns pontos se destacam. É por meio do sucesso alcançado que o empreendedor é discursivamente construído como "dono do seu destino", podendo minimizar as incertezas da vida. Constitui, assim, um herói que precisa ser copiado, contribuindo para a difusão de modismos de gestão que não questionam o reducionismo e os condicionantes ideológicos embutidos em suas informações. Nesse quadro, os empresários e os dirigentes empresariais não mais representam a exploração do homem pelo homem; convertem-se em símbolos do sucesso social, pois o lucro nada mais é do que "um excedente legítimo que não gera nem exploradores nem explorados, mas simplesmente ganhadores de um lado e malsucedidos ou perdedores do outro lado" (AKTOUF, 2004, p. 68). O discurso do fracasso, por sua vez, é produzido de forma silenciosa sob a forma do improdutivo, do estéril, da preguiça, da desqualificação profissional, da ideia não implementada. É nesse sentido que os discursos 
apresentam aspectos de controle social, pois realidade, ideologia e ficção se misturam e são disseminados nas histórias de sucesso.

A terceira ordem de discurso - a ausência de alternativas viáveis ao capitalismo contemporâneo - elege apenas um caminho possível: o empreendedorismo como impulsionador do desenvolvimento econômico baseado na lógica de livre concorrência capitalista. Tal inexorabilidade é questionável, já que as próprias ordens de discurso pressupõem um equilíbrio instável, ocorrendo articulações e rearticulações em função dos embates por posições hegemônicas (FAIRCLOUGH, 2003). Como os discursos não apenas refletem, mas constroem as relações sociais esse processo não é monolítico e sem alternativas. Há limites quanto à reprodução dos discursos hegemônicos, uma vez que, não constituem apenas representações de realidades existentes, mas também representações imaginárias, projeções de possíveis realidades alternativas, visões de futuros possíveis, bem como distorções de realidades existentes (FAIRCLOUGH; THOMAS, 2004).

Consenso, exemplo e inexorabilidade. As três ordens de discursos identificadas contribuem, de forma ideológica, para que a empresa capitalista contemporânea seja compreendida como único modelo possível de geração de riqueza, de renda e de trabalho na sociedade. Refletir sobre tais discursos hegemônicos nos leva a indagar se preparamos, como educadores, nossos jovens para a vida ou para o mercado de trabalho. Esse estudo indica que os preparamos apenas para o mercado por meio da visão - ideológica - de que, ao assim procedermos, o estamos preparando para a vida.

Em outras palavras, legitimamos o transbordamento da esfera do mercado para a esfera da vida. E ao assim procedermos, o conhecimento produzido nas universidades passa a ser considerado apenas mais um complemento do cotidiano empresarial, reduzindo o peso da reflexividade acadêmica. Diante disso, cabe refletir sobre a orientação da educação superior para que a ideologização do empreendedor não reduza a importância da universidade (CONTU, 2009) e para garantir que instituições acadêmicas não apóiem, sem querer, interesses empresariais em suas práticas de ensino. Se a educação não é uma mercadoria, é preciso relativizar a preparação para o mundo do trabalho de forma que esta não seja um mecanismo de reprodução do capital e sim uma forma de emancipação humana.

\section{Referências}

AIDAR, M. Empreendedorismo. São Paulo: Thomson Learning, 2007.

AKTOUF, O. Pós-Globalização, Administração e Racionalidade Econômica. São Paulo: Atlas, 2004. 
ARMSTRONG, P. Critique of entrepreneurship: people ad policy. New York: Palgrave MacMillan, 2005.

AUDIA, P. G.; RIDER, C.I. Entrepreneurs as organizational products: revisited. In: BAUM, R.; FRESE, M.; BARON, R. (Orgs.) The psycology of entrepreneurship. Lawrence Erlbaum Associates, 2005.

BOAVA, D.L.T.; MACEDO, F.M.F. Sentido Axiológico do Empreendedorismo. Encontro Nacional dos Cursos de Pós-Graduação em Administração, 33, 2009. Anais... São Paulo: ANPAD, 2009.

BOJE, D. M; OSWICK, C.; FORD, J.D. Language and organization: the doing of discourse. Academy of Management Review. v. 29, n. 4, p. 571$577,2004$.

BOLTANSKI, L; CHIAPELLO, E. The new spirit of capitalism. New York: Verso, 2007.

BRITTAIN, J. W.; FREEMAN, J. Entrepreneurship in the semiconductor industry. 1986.

BYGRAVE, W.; HOFER, C. Theorizing about entrepreneurship. Entrepreneurship Theory and Practice, v. 16, n.2, p. 13-22, 1991.

CHOMSKY, N. Profit over people: neoliberalism and global order. New York: Seven Stories Press, 2011.

CHOULIARAKI, L.; FAIRCLOUGH, N. Critical discourse analysis in organizational studies: towards an integrationist methodology. Journal of Management Studies, v. 47, n. 8, p. 1213-1218, 2010.

COSTA, A.M.; BARROS, D.F.; CARVALHO, J.L.F. A Dimensão Histórica dos Discursos acerca do Empreendedor e do Empreendedorismo. Revista de Administração Contemporânea, v. 15, n. 2, p. 179-197, 2011.

DENZIN, N. K.; LINCOLN, Y. S. Introduction: the discipline and practice of qualitative research. In: DENZIN, N. K.; LINCOLN, Y. S. Collecting and interpreting qualitative materials. Thousand Oaks: Sage, 2008.

DORNELAS, J. C. A. Empreendedorismo: transformando idéias em negócios. Rio de Janeiro: Elsevier/Campus, 2008.

ESSERS, C.; BENSCHOP, Y. Enterprising identities: female entrepreneurs of Moroccan and Turkish origin in the Netherlands. Organization Studies, v. 28, n. 1, p. 49-69, 2007.

FAIRCLOUGH, N. Discourse and social change. Hoboken: John Wiley, 1993.

Revista Brasileira de Estudos Organizacionais • v. 1. n. 2, p. 187-211, dez. 2014, eISSN: 2447-4851

Sociedade Brasileira de Estudos Organizacionais 
FAIRCLOUGH, N. Analysing discourse: textual analysis for social research. London: Routledge, 2003.

FAIRCLOUGH, N.; THOMAS, P. The discourse of globalization and the globalization of discourse. In D. GRANT, C.HARDY, C. OSWICK, \& L. PUTNAM (Eds.). The Sage handbook of organizational discourse. London: Sage, 2004, p. 379-396

GARTNER, W. Who is an entrepreneur? Is the wrong question. Entrepreneurship Theory and Practice, v. 13, n. 4, p. 47-68, 1989.

GARUD, R.; HARDY, C.; MAGUIRE, S. Institutional entrepreneurship as embedded agency: an introduction to the special issue. Organizational Studies, v. 28, 2007.

GASKELL, G. Individual and group interviewing. In: BAUER, M.; GASKELL, G. (Ed.). Qualitative researching with text, image and sound: a practical handbook for social research. Thousand Oaks: Sage, 2000.

GAULEJAC, V. La société malade de la gestion: idéologie gestionnaire, pouvoir managérial et harcèlement social. Paris: Seuil, 2005.

GRANT, D.; KEENOY, T.; OSWICK, C. Organizational discourse. International Studies of Managment \& Organization, v. 31, n. 3, p. 5-24, 2001.

GRÉGOIRE, D.; DÉRY, R.; BÉCHARD, J.-P. Evolving conversations: a look at the convergence in entrepreneurship research. Paper presented at the Babson Kaufmann Frontiers of Entrepreneurship Research Conference, Jönköping, Sweden, 2001

HARDY, C. Researching organizational discourse. International Studies of Managment \& Organization. v. 31, n. 3, p. 25-47, 2001.

HARVEY, D. The condition of postmodernity: an enquiry into the origins of cultural change. Hoboken: Wiley-Blackwell, 1991.

KETS DE VRIES, M. F. R. The entrepreneurial personality: person at the crossroads. Journal of Management Studies, v. 14, p. 24-58, 1977.

KHAN, F.R.; MUNIR, K.A.; WILLMOTT, H. A Dark Side of Institutional Entrepreneuship Soccer Balls, Child Labour and Postcolonial Impoverishment. Organization Studies, v. 28, n. 7), p. 1055-1077, 2007.

KRUGER, N. F.; BRAZEAL, D. V. Entrepreneurial potential and potential entrepreneurs, Entrepreneurship Theory and Practice, v. 18, n. 3, p. 91104, 1994. 
LEITCH, S.; PALMER, I. Analysing texts in context: current practices and new protocols for critical discourse analysis in organization studies. Journal of Management Studies. v. 47, n. 8, p. 1194-1212, 2010.

LUMPKIN, G.T., DESS, G.G. Clarifying the entrepreneurial orientation construct and linking it to performance. Academy of Management Review, v. 21, n. 1, p. 135-172, 1996.

MCCHESNEY, R. W. Introduction. In: CHOMSKY, N. Profit over people: neoliberalism and global order. New York: Seven Stories Press, 2011.

MCLAREN, P. L. Revolutionary multiculturalism: pedagogies of dissent for the new millennium. Boulder: Westview, 1997.

MESZAROS, I. Beyond capital: toward a theory of transition. New York: Monthly Review Press, 2000.

MINTZBERG, H. Strategy making in three modes. California Management Review, v. 16, n. 2, p. 44-53, 1973.

MINTZBERG, H.; AHLSTRAND, B.; LAMPEL, J. Strategy safari: a guided tour through the wilds of strategic management. New York: Free Press, 1998.

MUTCH, A. Reflexivity and the Institutional Entrepreneur: A Historical Exploration. Organization Studies, v. 28, n. 7, p. 1123-1140, 2007.

OGBOR, J. O. Mythicizing and reification in entrepreneurial discourse ideology-critique of entrepreneurial studies. Journal of Management Studies, v. 37, n. 5, 2000.

PARKINSON, C.; HOWORTH, C. The language of social entrepreneurs. Lancaster University Management School Working Paper, v. 32, 2007.

SANTOS, B.S. Produzir para viver: os caminhos da produção nãocapitalista. Rio de Janeiro: Record, 2002.

SANTOS, F. M.; EISENHARDT, K. M. Constructing markets and shaping boundaries: entrepreneurial power in nascent fields. Academy of Management Journal, v. 52, n. 4, p. 643-671, 2009.

SCHRAMM, C.; LITAN, R. E. The growth solution. The American, p. 3238, jul/ago, 2008.

SCHUMPETER, J. (1911). A Teoria do Desenvolvimento Econômico. Os Economistas. São Paulo: Editora Abril, 1982. 
SOMBART, W. [1902]. El apogeo del capitalismo. Vol I. México: Fondo de Cultura Economica. 1946.

SORENSON, O; AUDIA, P. G. The social structure of entrepreneurship activity: geographic concentration of footwear production in the United States, 1940-1989. American Journal of Sociology, v. 106, n. 2, p. 424-462, 2000.

WALKER, R. Marxism-Leninism as discourse: the politics of the empty signifier and the double blind. British Journal of Political Science, v. 19, n. 2, p. 161-189, 1989. 